\title{
Bupivacaine and lignocaine for ophthalmic surgery
}

\author{
E OJI, AND A OJI'
}

From the 'Department of Ophthalmology and the ${ }^{2}$ Department of Anaesthesia, University of Jos, Nigeria

SUMMARY Bupivacaine $0.5 \%$ when used as a local anaesthetic for ocular cataract surgery does not give absolute ocular akinesia but provides adequate and prolonged pain relief. In comparison lignocaine provides good ocular akinesia at operation but pain relief is short lived. The mixture of the two local anaesthetics in equal volumes eliminated the disadvantages of their individual use.

General anaesthesia has replaced local anaesthesia in ophthalmic surgery for a number of reasons; patient co-operation is not required, delicate and prolonged surgery can be undertaken, and there is no risk of retrobulbar haemorrhage. It requires special equipment and preparation of the patient, and care and specialist anaesthetists that may not be available in developing countries. Local anaesthesia with either of the amides lignocaine or bupivacaine (Fig. 1) still has a place in the choice of anaesthetic for a poor risk patient. With the availability of a long acting drug such as bupivacaine, prolonged surgery can be performed, ${ }^{1-3}$ and postoperative analgesia is assured.

In the present study the adequacy of analgesia, operating conditions, and complications were compared for three drug regimens under standard operating conditions. The retrobulbar block was performed with either lignocaine or bupivacaine or a mixture of lignocaine and bupivacaine according to a predetermined protocol.

The success of any nerve block depends on the operator, who requires a thorough knowledge of the anatomy. Diffusion of drugs is restricted by anatomical boundaries, and correct placement of drugs leads to a smaller dose being necessary. The study was therefore designed for blocks to be performed solely by the operator, so as to use the minimal doses of the various local anaesthetics to give acceptable ocular anaesthesia and akinesia.

\section{Material and methods}

Ninety adult consenting patients were allocated randomly to one of three groups $(\mathrm{A}, \mathrm{B}$, and $\mathrm{C}), 30$ patients in each group. Group $A$ had their cataract surgery performed under bupivacaine as the local

Correspondence to Revd Professor E O Oji, FRCS, University of Jos Medical School, Jos, Plateau State, Nigeria. anaesthetic. Group B had their cataract surgery under lignocaine, and in group $\mathrm{C}$ a mixture of lignocaine and bupivacaine was administered.

Each patient received $75 \mathrm{mg}$ of pethidine intramuscularly one hour preoperatively to provide minimal sedation and analgesia. Thirty minutes before surgery each patient also received topical drops of $0.4 \%$ oxybuprocaine to the eye for surgery every 5 to 10 minutes till the operation began.

Group A patients received $1.5 \mathrm{ml}$ of $0.5 \%$ bupivacaine through a retrobulbar needle, $4.0 \mathrm{ml}$ of $0.5 \%$ bupivacaine at the stylomastoid foramen and around the parotid distribution of the facial nerve for the seventh cranial nerve block, and $0.5 \mathrm{ml}$ of $0.5 \%$ bupivacaine each to the upper and lower lids for paralysis immediately before surgery.

Similarly, group B patients received $1.5 \mathrm{ml}$ of $2 \%$ lignocaine retrobulbarly, $4.0 \mathrm{ml}$ of $2 \%$ lignocaine for the facial nerve block and $0.5 \mathrm{ml}$ of $2 \%$ lignocaine each to the upper and lower lids.

For the group $\mathrm{C}$ patients a mixture of $0.5 \%$ bupivacaine $3.5 \mathrm{ml}$ and $2 \%$ lignocaine $3.5 \mathrm{ml}$ was used. The two were thoroughly mixed before the

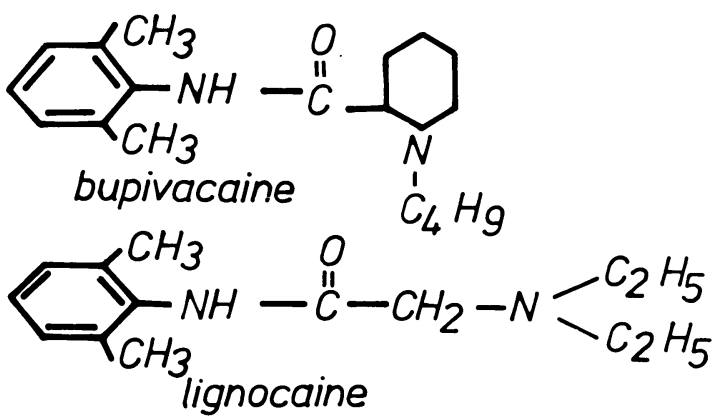

Fig. 1 Structural formulae of the amides Bupivacaine and lignocaine. 
injections were given. The retrobulbar injection was $1.5 \mathrm{ml}$ of the mixture, $4.0 \mathrm{ml}$ was used for the facial nerve block and $1.0 \mathrm{ml}$ for the two lids.

All the patients used in this study had uncomplicated senile cataract which was extracted intracapsularly by the ab-externo incision. Cataract extraction was with the Amoilette cataract cryoprobe, and magnification was between 10 and 16 times under the Wild Heerburg M650 coaxial operating microscope. All procedures were standardised, and the first author performed all the surgery.

The presence or absence of ocular movements after each type of local anaesthetic was recorded by the naked eye and the operating microscope. In selected cases the eye movements were recorded with a video camera for subsequent study and classified as OVC/16a University of Jos and stored at the Medical Instructional Technology Unit. Records of eye movements were taken just before the placement of a superior rectus muscle suture and again after clearing the limbus, before the corneoscleral incision to enter the anterior chamber. After cataract extraction eye movements were further observed before reapposition of the corneoscleral wound and before the removal of lid sutures. Postoperatively the time each patient complained of pain necessitating relief with paracetamol was recorded, and the frequency of demand of postoperative pain relief was also recorded by the nurse.

\section{Results}

\section{EYE MOVEMENTS}

The results are recorded in Table 1. In Group A, who had bupivacaine alone, $37 \%$ of the patients had noticeable eye movements during surgery, both before and after cataract extraction, and these proved troublesome to the operator. Movements of this type occurred in $17 \%$ of patients who received lignocaine alone (group B), and in the same group just before removal of the lid sutures three patients developed a tremulous lower lid (muscle fasciculation) which did not interfere with the procedure. Almost all the patients in group $\mathrm{C}$ had akinesia before and after extraction of the cataract, except for two patients whose movements were so minimal that they were noticed only under the operating microscope at a moderate magnification of 16 times before the corneoscleral incision. These movements were abolished during the postcataract extraction periods of observation.

\section{PAIN RELIEF}

Groups $\mathrm{A}$ and $\mathrm{C}$ showed little demand for pain relief for up to 12 hours postoperatively (Table 2). By this time all the patients in group $B$, the group receiving
Table 1 Frequency of eye movements, mild or moderate, in the three groups each with 30 patients

\begin{tabular}{llll}
\hline & $\begin{array}{l}\text { Group A } \\
\text { (bupivacaine) }\end{array}$ & $\begin{array}{l}\text { Group B } \\
\text { (lignocaine) }\end{array}$ & $\begin{array}{l}\text { Group C } \\
\text { (bupivacaine+ } \\
\text { lignocaine) }\end{array}$ \\
\hline Moderate eye & & & \\
$\quad$ movements & 11 & 5 & 0 \\
Mild eye movements & 0 & 3 & 2 \\
Absolute akinesia & 19 & 22 & 28 \\
Totals & 30 & 30 & 30 \\
\hline
\end{tabular}

lignocaine alone, had required analgesia. The group B patients who required analgesia in the first six hours received it two to three hours postoperatively.

\section{COMPLICATIONS}

There were no immediate or postoperative complications of the nerve block. All nerve blocks provided analgesia at the time of operation, and return of sensation occurred in all patients.

\section{Discussion}

Lignocaine and bupivacaine are both local anaesthetic amides but they differ in their physicochemical properties. Bupivacaine is highly protein bound, $94 \%$ being bound to plasma protein compared with $64 \%$ lignocaine at the same plasma concentration. ${ }^{4}$ The long duration of action of bupivacaine has been related to its tissue binding properties. ${ }^{5}$

This study showed that for postoperative pain relief bupivacaine when used as a local anaesthetic for ocular surgery gives adequate and prolonged ocular analgesia. The use of lignocaine alone was associated with a rapid return of pain, and more than half of the patients in this group required analgesia within the first two to three hours after surgery.

The rate of onset of action of a local anaesthetic drug depends on its degree of ionisation at tissue $\mathrm{pH}$, that is, its pKa. Lignocaine has a pKa of 7.87 and has a mean onset of action of three minutes because up to $30 \%$ may be in the non-ionised form. Bupivacaine has a pKa of 8.05 , so that at tissue $\mathrm{pH}$ less of the drug is non-ionised (about $10 \%$ ) and its duration of onset

Table 2 Time after the operation when the first analgesia was administered to the patients, 30 patients in each group

\begin{tabular}{llll}
\hline & $\begin{array}{l}\text { Group A } \\
\text { (bupivacaine) }\end{array}$ & $\begin{array}{l}\text { Group B } \\
\text { (lignocaine) }\end{array}$ & $\begin{array}{l}\text { Group C } \\
\text { (bupivacaine+ } \\
\text { lignocaine) }\end{array}$ \\
\hline Less than 6 hours & 6 & 17 & 0 \\
6 to 12 hours & 0 & 13 & 6 \\
More than 12 hours & 24 & 0 & 24 \\
Totals & 30 & 30 & 30 \\
\hline
\end{tabular}


of action is longer. ${ }^{6}$ In this study the slow onset of action of bupivacaine did not affect the time for surgery to begin because the time between the block and the incision was dependent on other surgical factors.

Another difference between lignocaine and bupivacaine at the concentration used related to the quality of the block. Bupivacaine $0.5 \%$ is associated with a sensory block but the motor blockade is slight. The motor blockade is increased by increasing the concentration of bupivacaine, ${ }^{7}$ but this solution was not available to the author. It was observed that in group A with bupivacaine alone there was adequate ocular analgesia but not absolute akinesia. The $0.75 \%$ bupivacaine concentration when administered alone ${ }^{2}$ showed a delay in onset of akinesia of more than 15 minutes. Lignocaine when used alone gave better ocular akinesia, but pain relief was less effective.

The group C patients, who received a 50/50 volumetric mixture of bupivacaine and lignocaine, had the best results both for akinesia and for pain relief. The method minimised the disadvantages experienced in the use of these two local anaesthetic agents individually.

The use of adrenaline with the drugs was considered. Toxic effects are related to systemic absorption or accidental intravascular injection and for amide-amide mixtures are additive. Mixtures of lignocaine and bupivacaine are used for brachial plexus block and epidural block, ${ }^{8}$ but no single mixture had been advocated. It has been established that $0.5 \%$ bupivacaine and $2 \%$ lignocaine with adrenaline give comparable blockades. ${ }^{9}$ The addition of adrenaline to bupivacaine is not necessary to improve the nerve blockade, and the resulting $\mathrm{pH}$ of a solution with adrenaline is more acid, so that it has an even slower onset of action. The mixture chosen proved to be adequate, but a nerve blockade with a higher concentration of bupivacaine might have proved to be more suitable.
A bupivacaine and lignocaine mixture has been used in retinal detachment surgery ${ }^{10}$ to give satisfactory operating conditions in $90 \%$ of cases. Its use in cataract surgery in this study, it should be noted, was with a small volume, $1.5 \mathrm{ml}$, injected through the retrobulbar needle and with a lower concentration than that used in other studies. ${ }^{1-3}$

We recommend the use of a $50 / 50$ volumetric mixture of lignocaine and bupivacaine for ocular surgery in places where general anaesthesia is unavailable, dangerous, and costly.

We acknowledge the valuable assistance by both the theatre and ward nurses of the ophthalmic department and the technical aid from the Medical Instructional Technology Unit for the video records and the black-and-white prints. Finally we thank $\mathrm{Mr}$ Emmanuel Ikoroh for his secretarial assistance.

\section{References}

1 Pearce JL. General and local anaesthesia in eye surgery. Trans Ophthalmol Soc UK 1982; 102: 31-4.

2 Chin G, Almquist HD. Bupivacaine and lidocaine retrobulbar anesthesia: a double blind clinical study. Ophthalmology (Rochester) 1983; 90: 369-72.

3 Gills JP, Rudisill JE, Bupivacaine in cataract surgery. Ophthalmic Surg 1974; 5: 67-70.

4 Tucker GT, Boyes RN, Bridenbaugh PO, Moore DC. binding of anilide type Local anaesthetics in human plasma: 1. Relationships between binding, physicochemical properties and anaesthetic activity. Anesthesiology 1970; 33: 287-303.

5 Wilkinson GR, Lund PG. Bupivacaine levels in plasma and cerebrospinal fluid following peridural administration. Anesthesiology 1970; 33: 482-6.

6 Bromage PR. Epidural analgesia. Philadelphia: Saunders, 1978: 79,80 .

7 Bromage PR. Epidural analgesia. Philadelphia: Saunders, 1978: 305.

8 Bromage PR. Epidural analgesia. Philadelphia: Saunders, 1978: 321.

9 Watt MJ, Ross DM, Atkinson RS. A clinical trial of bupivacaine. Anaesthesia 1968; 23: 2.

10 Holekamp TLR, Arribas NP, Bonuk I. Bupivacaine Anesthesia in Retinal Detachment Surgery. Arch Ophthalmol 1979; 97: 109-11.

Accepted for publication 24 April 1986. 